\title{
Cobrança pelo uso da água: a experiência internacional e brasileira como referenciais para o Estado do Rio Grande do Sul
}

\author{
Marcos Vinicius Godecke' \\ 'Professor no curso de Gestão Ambiental, Universidade Federal de Pelotas, Pelotas, RS Brasil
}

\section{Resumo}

Utilizando pesquisa bibliográfica e documental, complementada por entrevistas e acompanhamento de reuniões públicas, este estudo investiga a experiência internacional e brasileira da cobrança pelo uso da água como instrumento econômico de gestão, com vistas a sua aplicação no estado do Rio Grande do Sul. A revisão da literatura mostrou o marco regulatório do Estado, a Lei 10350/1994, ainda alinhado às melhores práticas e aponta aspectos a serem observados para que a aplicação do instrumento induza os usuários às práticas necessárias para o atingimento e manutenção da qualidade e quantidade dos mananciais nos níveis desejados.

Palavras-chave: Cobrança pelo uso da água, instrumentos econômicos, gestão de recursos hídricos, Rio Grande do Sul.

\begin{abstract}
Using literature and document research, complemented by interviews and monitoring of public meetings, this study investigates the international and brazilian experience of charging for water use as an economic instrument of management, for its application in the state of Rio Grande do Sul. The literature review showed the regulatory state, the Law 10350/1994, still aligned with best practices and points to aspects to be observed that the application of the instrument induces users to necessary practices for the achievement and maintenance of the water quality and quantity at desired levels.
\end{abstract}

Keywords: Charging for water use, economic instruments, management of water resources, Rio Grande do Sul. 


\section{INTRODUÇÃO}

A motivação para a escrita deste artigo surgiu da leitura do Plano da Bacia Hidrográfica do Rio dos Sinos, situada no estado do Rio Grande do Sul (RS). O histórico de poluição daquele manancial hídrico é tão relevante que o clamor social tornou-o pioneiro: foi o primeiro comitê de bacia hidrográfica constituído no Brasil, em 1987. Passados 25 anos, ainda não possui um plano de bacia acabado1. Entre as ações previstas no texto atual, a de número 8.2 trata das diretrizes para a cobrança pelo uso da água (doravante chamada apenas de cobrança) na bacia, porém apenas informa que aguardará as diretrizes a serem definidas no Plano Estadual de Recursos Hídricos (PERH) e enumera os obstáculos e dificuldades previstas para a implantação da cobrança: (i) interfaces institucionais, (ii) inexistência de uma Agência de Águas atuando em caráter permanente, (iv) a necessidade de definições de natureza mais ampla (PERH) e (iv) "a sociedade da Bacia possivelmente não estará simpática a uma nova cobrança e reações enfáticas devem ser esperadas" (UNISINOS, [2011], pg.237).

Fica clara a percepção daqueles autores da inexistência de uma estrutura institucional avançada ao nível da aceitação de instrumentos mais complexos de gestão, como a cobrança. A mesma conclusão foi encontrada por Souza et al. (2009) ao estudar os conflitos pelo uso da água na contígua bacia hidrográfica $(\mathrm{BH})$ do lago Guaíba. Fica evidenciada a dificuldade de evolução da gestão local das BH sem o apoio de Agências de Águas e definições legais como as diretrizes para a cobrança. De fato, a implantação da cobrança demanda a existência de uma Agência de Bacias apta a prestar os serviços de operacionalização da cobrança, além de um cadastro atualizado de usuários, tanto pelo lado da captação como de descarga (diluição) de efluentes e adequado controle das outorgas. Então, a plena aplicação de instrumentos econômicos de gestão pelos comitês de bacias depende da evolução institucional do tema em nível estadual. Tais circunstâncias remetem a discussão da aplicação do instrumento da cobrança para a esfera estadual, onde o PERH encontra-se em fase de elaboração e não há Agências de Águas operando em caráter permanente.

Neste cenário, poderá a cobrança resultar em instrumento útil na busca da sustentabilidade dos recursos hídricos? Diante da expectativa de reações enfáticas à adoção da cobrança, que estratégia pode ser adotada para esta implementação? À luz da experiência internacional e brasileira, que cuidados devem ser adotados de modo que a adoção da cobrança alcance a eficiência esperada na indução dos usuários ao uso sustentável da água? Utilizando pesquisa bibliográfica e documental, complementada por entrevistas e acompanhamento de reuniões públicas, este estudo busca trazer elementos que qualifiquem esta discussão. Para tanto, além desta introdução e das considerações finais, o artigo está dividido em cinco seções, a primeira contextualiza de forma ampla a situação das águas no Brasil. A segunda apresenta a cobrança pelo uso da água como instrumento de política ambiental. Na terceira e quarta seções são apresentadas experiências europeias e brasileiras desta cobrança, como subsídio para o estudo do caso do RS, apresentado na quinta seção.

\section{SITUAÇÃO ATUAL, TENDÊNCIAS E DESAFIOS DA GESTÃO DE RECURSOS HÍDRICOS}

Segundo Zafar Adel, presidente da ONU-Água (apud Bicudo et al., 2010), a água, pelo impacto que exerce em nossas vidas, na sociedade, sistemas naturais e habitats, mereceria um lugar mais central nos debates sobre temas como segurança alimentar e mudanças climáticas. De fato, relatórios da Organização das Nações Unidas (ONU) calculam em 884 milhões o número de pessoas que utilizam fontes não tratadas para o seu abastecimento de água e 2,6 bilhões sem acesso ao saneamento básico. Se consideradas as normas definidas em resolução da ONU de 2010, sobre o direito humano fundamento de acesso à água segura e ao saneamento, estes números sobem para entre 3 e 4 bilhões (UNESCO, 2012). Entre as consequências da falta de saneamento está que quase $90 \%$ dos cerca de 4 bilhões de episódios anuais de diarreia são atribuídos a deficiências no esgotamento sanitário e na água disponibilizada para o consumo público (BICUDO et al., 2010).

A publicação "Águas do Brasil" apresenta uma visão clara e contundente da situação dos

1 Publicado no final de 2011, o plano da Bacia Hidrográfica do Rio dos Sinos apresenta resultados parciais. Entre as pendências está a necessidade da revisão do enquadramento das águas da bacia (UNISINOS, [2011]). 
recursos hídricos no Brasil, e os caminhos de gestão a serem trilhados. Em busca de uma síntese, os organizadores do estudo - Carlos Bicudo, José Tundisi e Marcos Scheuestuhl - concluem que o panorama é cinzento. Ao tempo em que destacam a evolução na gestão dos recursos hídricos verificadas nos últimos 30 anos, questionam como a sociedade brasileira poderá enfrentar a escassez de água num futuro próximo, diante de problemas como as disparidades geográficas da distribuição dos recursos hídricos no país, o aumento dos conflitos pelos recursos naturais (ar, água e terra) decorrentes da urbanização, a crescente exploração das águas subterrâneas, e o agravamento dos efeitos das mudanças climáticas. Entre as proposições destacadas pelos organizadores a partir da contribuição de diversos autores nos diferentes temas desenvolvidos no livro estão: (i) a busca da universalização da prática do reuso da água pela indústria através da promulgação de um arcabouço legal realista, que possa ser efetivamente implementado através dos comitês de bacias hidrográficas; (ii) o disciplinamento no uso da água subterrânea pelo reconhecimento das áreas de maior demanda, avaliação dos perigos de superexploração e proteção quanto à contaminação antropogênica; (iii) a promoção de uma integração mais efetiva da ciência, tecnologia e inovação com a gestão integrada dos recursos hídricos e a governança da água; (iv) a aplicação de cenários e modelos - ecológicos e matemáticos - na escolha de oportunidades e alternativas de gestão; (v) avançar no monitoramento da qualidade e quantidade das águas superficiais e subterrâneas; (vi) organizar redes de estudos que integrem dados da qualidade de água com a saúde humana - informações epidemiológicas. No tocante às bacias hidrográficas, defendem: (vii) a descentralização da gestão; (viii) a organização e o suporte às agências de bacia; (ix) a inovação e organização com base em bancos de dados e séries históricas; (x) e a valoração econômica dos serviços ecossistêmicos como forma de acrescentar novas perspectivas ao uso de instrumentos econômicos para a gestão da água.

Embora cada um dos tópicos citados mereça aprofundamentos de abordagem, face as suas relevâncias, em vista do escopo deste estudo cabe o desenvolvimento da décima sugestão, relativa à valoração dos serviços ecossistêmicos, apresentada na próxima seção.

\section{A COBRANÇA PELO USO DA ÁGUA COMO INSTRUMENTO DE POLÍTICA AMBIENTAL}

Qual é o valor econômico de um recurso natural? Qual é a importância da sua mensuração? Estas questões poderiam ser irrelevantes caso a situação fosse de abundância dos recursos naturais. Ocorre que a partir da revolução industrial o crescimento populacional e econômico ocorreu em taxas exponenciais: a população planetária passou de um para sete bilhões de habitantes e a economia dos países foi multiplicada por mais de 33 vezes (CÁNEPA et al., 2010). Embora a degradação ambiental tenha acompanhado o homem ao longo da sua existência na terra, são os atuais volumes de exploração e degradação que preocupam, pois superam a capacidade de carga do planeta, resultando em escassez e malefícios com a perda da biodiversidade, redução de serviços sistêmicos e mudanças climáticas. Esta situação, que já compromete a existência de populações menos favorecidas, tende a se agravar para as gerações futuras. Nas palavras de Thomas e Callan (2010, p.13): "analisando retrospectivamente, agora nós reconhecemos que o trade-off entre qualidade ambiental e desenvolvimento econômico foi significativo".

Chama-se de externalidades aos efeitos a terceiros resultantes dos atos de produção ou consumo. Podem ser positivas ou negativas em função da geração de benefícios ou danos externos. Os custos resultantes das externalidades (negativas) são de difícil mensuração, podendo afetar contemporâneos e/ou alcançar gerações futuras, sem respeitar as fronteiras entre países, de modo que normalmente não são incorporadas aos preços, constituindo-se em "falhas de mercado".

A inexistência de mecanismos de mercado para incentivar a incorporação dos custos sociais aos custos privados de produção e consumo é resultado da ausência de direitos de propriedade sobre as externalidades, dando a elas o caráter de bens públicos que demandam intervenção governamental para a sua correção.

A atuação governamental para a correção das externalidades pode envolver a aplicação, individual ou combinada, de três tipos de políticas ambientais: instrumentos de comando e controle (C\&C), via legislação e fiscalização; instrumentos econômicos (IE) e instrumentos educacionais.

O objetivo dos IE não é arrecadar recursos, mas servir de estímulo econômico para a adequação dos comportamentos frente ao meio ambiente. Comparativamente aos $\mathrm{C} \& \mathrm{C}$, permitem considerar 
diferentes estruturas de custos dos agentes privados e podem mostrar-se mais eficientes, conciliando menores custos privados com maior eficiência ambiental2.

O valor econômico de um recurso ambiental pode incluir não apenas o valor de uso direto, mas outros componentes como o valor de uso indireto, representado pelas externalidades positivas; o valor de opção, resultante das suas características intrínsecas serem demandadas no futuro em usos diretos ou indiretos; e o simples valor da sua existência - valorizada por questões morais, culturais, éticas ou altruístas. O somatório destes valores resulta no valor econômico do recurso ambiental (VERA).

A precificação dos recursos ambientais pode ocorrer em três níveis. O primeiro é a cobrança pelo VERA, onde todas as externalidades negativas são incorporadas ao preço do recurso. Como o VERA é de difícil mensuração a alternativa pode ser a adoção do preço de financiamento. Neste caso a cobrança é utilizada para financiar a reparação de danos pré-existentes visando a recuperação da função ecossistêmica e às adequações aos processos de produção ou consumo de modo que atinjam, num prazo pré-estabelecido, as metas de uso do recurso natural. De maior abrangência está a doção do preço de indução, onde a precificação considera não apenas o preço de financiamento, mas alcança a indução dos usuários às práticas sustentáveis. No caso dos recursos hídricos, o preço de cobrança precisa superar o custo econômico das ações a serem implementadas pelos usuários visando à racionalização de uso (captação ou diluição) até o atingimento e manutenção dos níveis da qualidade e quantidades desejadas. Neste caso está-se adotando o critério de custo-efetividade, onde se considera que a racionalidade econômica levará os usuários a adotar a alternativa de menor dispêndio financeiro (MOTTA, 2006).

Devido às crescentes externalidades no uso dos recursos hídricos, os instrumentos de políticas adotados em grande parte dos países desenvolvidos, especialmente na Europa, apresentaram convergência em três aspectos: (i) crescente intervenção governamental, dando às águas o caráter de bem público; (ii) adoção de instrumentos econômicos para a aplicação dos princípios do usuário-pagador (PUP) e do poluidor-pagador (PPP); e (iii) adoção da precificação de acordo com o critério de custo-efetividade. O marco legal adotado pelo Brasil, inspirado na experiência alemã e francesa, apresenta consonância com estes aspectos (CÁNEPA et al., 2010).

A aplicação do IE relativo à cobrança implica na adoção dos dois princípios: o Princípio do Usuário Pagador (PUP) pela captação de água do manancial para uso industrial, agrícola e abastecimento urbano e o Princípio do Poluidor Pagador (PPP), pela diluição de efluentes industriais e esgotos urbanos.

Com relação ao uso para captação há necessidade de se conhecer as demandas de cada setor envolvido e as vazões dos corpos d'água. Segundo Cánepa et al. (2010), só haveria necessidade da cobrança em períodos de escassez, onde a vazão mínima não fosse suficiente para suprir a necessidade de todos os usuários captadores, buscando a aplicação de critérios de eficiência e otimização pela determinação das quantidades que cada setor captará aos diversos preços possíveis. Aos poluidores seria aplicado o mecanismo de custo-efetividade, com a elevação periódica dos preços associada a metas de redução de poluentes, customizadas por fonte, até que a qualidade da água atinja os níveis planificados. Os valores arrecadados de fontes que não conseguiram se ajustar às metas podem ser repassados, em forma de financiamento, aos poluidores que queriam evitar a cobrança pela prévia adequação das emissões, inclusive antecipando-se a futuros patamares legais.

A cobrança vem sendo largamente utilizada pelos países desenvolvidos. A próxima seção busca resgatar aspectos da experiência europeia aplicáveis ao Brasil.

\section{A EXPERIÊNCIA INTERNACIONAL NA COBRANÇA PELO USO DA ÁGUA}

Na União Europeia (UE) a diretiva 2000/60 estabeleceu as normas para a proteção das águas interiores, de transição, costeiras e subterrâneas visando: evitar a continuação da degradação, proteção e melhoria dos ecossistemas; a promoção do consumo sustentável; redução de descargas; e mitigação de inundações e secas. Esta legislação, com seus anexos, é um verdadeiro manual de normas e procedimentos. Com o título de "amortização dos custos dos serviços hídricos", o artigo nono orienta para os Estados-membro para o estabelecimento de preços que cubram o custo dos serviços, inclusive

2 A discussão sobre a conveniência da adoção de instrumentos C\&C e/ou econômicos é encontrada em Almeida, [199-?]. 
ambientais. Foi dado prazo até 2010 para que as políticas de preços deem incentivos adequados para que os consumidores utilizem eficazmente a água, e assim contribuam para os objetivos ambientais da diretiva. A abordagem está de acordo com o princípio geral da política ambiental da UE de alcançar preços que permitam a internalização completa das externalidades decorrentes da atividade antrópica (UE, 2000).

Embora de ampla utilização, conforme demonstra a Tabela 1, a cobrança pela captação de água não é generalizada na Europa. EEA (2005) informa que os modelos apresentam diferenças de formatação e, na maioria das vezes, não foram introduzidos por considerações ambientais, mas pelo potencial de geração de receita. Países como Dinamarca, França, Alemanha, Países Baixos e Reino Unido cobram taxas ou impostos, estabelecidos de forma articulada com o licenciamento, em geral incidindo sobre a quantidade autorizada ou sobre a quantidade efetivamente captada. Em alguns casos é ponderada a qualidade da água e em outros há distinção entre águas superficiais e subterrâneas. Normalmente são consideradas na fixação das taxas tipos de usuários e os fins a que a se destina. $\mathrm{Na}$ Dinamarca a tributação fez parte de uma reforma fiscal ocorrida em 1994, os resultados demonstraram nítidas reduções na demanda. A indústria e a agricultura foram excluidas da tributação para evitar impactos negativos na competitividade. Na Holanda a cobrança abrange aguas subterrâneas e auto-abastecimento. São tributados consumidores ligados ao serviço público com consumo superior a 300 m3 por ligação/ano. Na Inglaterra e no País de Gales as taxas de captação estão ligadas às licenças, calculadas em função da quantidade máxima de água a ser captada pelos utilizadores. As taxas de captação variam regionalmente em função dos custos de administração e regulação calculados pelos ramos regionais da agência ambiental. O mecanismo é questionado por não garantir uma concorrência mais justa entre empresas de diferentes regiões. Como a taxa foi projetada apenas para cobrir custos, as próprias empresas distribuidoras argumentam que não há estímulo financeiro para seus clientes reduzirem a demanda (EEA, 2005; Ecotec, 2001).

No tocante à diluição de efluentes, conforme demonsra a Tabela 1, a cobrança é um instrumento comum utilizado em países europeus para regular as descargas de efluentes em águas naturais. Segundo EEA (2005), existem grandes diferenças de modelagem, tornando a comparação entre os sistemas quase impossível. As diferenças dizem respeito aos regimes de taxas, incluindo a abordagem de cálculo do passivo e base para a imposição. Em geral, a responsabilização do poluidor é calculada sobre a carga de substâncias poluidoras, na maioria das vezes em pequeno número, mas que podem ultrapassar a trinta poluentes deferentes, como é o caso da Romênia. Alguns sistemas cobrem apenas descargas diretas em águas superficiais (Dinamarca, Alemanha, Espanha e Reino Unido), enquanto outros incluem as descargas indiretas - aquelas que recebem algum tratamento prévio à emissão (Bélgica, França e Países Baixos). Em vários países - Bulgária, Estônia, Polônia e Eslováquia, a cobrança somente ocorre quando a concentração de poluentes exceder a níveis previamente definidos. Estas taxas podem chegar a 25 vezes a taxa básica, como no caso da Rússia e, dependendo da periculosidade do poluente, em até 300 vezes, como no caso da Lituânia. Algumas tarifas foram projetados para incentivar a redução da poluição, como na Alemanha. A cobrança em países como a Bélgica, França e Países Baixos tem uma dupla função: cobrir os custos de coleta e tratamento, e financiar investimentos relacionados com a água. Na Holanda a função primária é de financiamento, mas apresenta valor suficientemente elevado para estimular a redução. Os IE para a proteção da água estão em vigor na maioria dos países balcânicos, geralmente incidentes sobre o volume de efluente descarregado, com diferenciação de preços de acordo com o tipo de poluidor. Na Bósnia-Herzegovina, a base de cálculo relaciona a quantidade diária de poluição por habitante com o tamanho da população. Segundo EEA (2005), nestes países os IE não desempenham um papel importante na gestão da poluição da água, por razões que incluem falhas de projeto, má qualidade de implementação e o baixo nível das taxas.

Com relação aos fundos ambientais formados com a cobrança, na região central e países do leste europeu a tendência é de um uso abrangente, fornecendo meios financeiros para uma ampla gama de necessidades ambientais. Ao contrário, em países como a Bélgica, França e Alemanha, os recursos captados têm objetivos claramente definidos e ação setorial. Porém a captação sofre redução por conta de disposições legais concedidas a indústrias intensivas em água visando mitigar o risco de perda de competitividade na comparação com as concorrentes em países estrangeiros (EEA, 2005).

Como a cobrança não é um tributo, mas IE que visa adequar o comportamento dos usuários dos recursos hídricos, cabe o questionamento se a cobrança que vem sendo praticada nos diversos casos expostos traz resultados efetivos. Colocando esta questão como central em seu estudo, Santos 
Tabela 1 - Visão geral da cobrança pela água na Europa em 2005

\begin{tabular}{|c|c|c|c|c|c|}
\hline Pail & Coflopin & Dilniç. & Pai. & Ceftroin & Dilnipīo \\
\hline Alb= & NEo & Sim & HFlia & sim & Sim \\
\hline Alemphn & Sim & Sim & Letiminie & Sim & Sim \\
\hline Antrin & $\mathbf{N E} \mathbf{0}$ & Sim & Liechtenstein & Sim & $5 \mathrm{~mm}$ \\
\hline Belgin & NEs & Sim & Limminie & Sim & Sim \\
\hline Bielkmíxis & Sm & Sm & Laxemburgo & $\mathbf{N E}$ & NGP \\
\hline $\begin{array}{l}\text { Bónmia e } \\
\text { Hevog grina }\end{array}$ & Sin & Sim & Manedtonia & Sim & Sim \\
\hline Bulfínia & Sim & Sim & Malta & Sim & Nop \\
\hline Chipre & $\mathbf{N E} \mathbf{0}$ & Sim & Maldária & Sim & Sim \\
\hline Croúcia & NEo & NGp & Nornesa & NEo & Sim \\
\hline Dim-mincm & Sim & Sim & Ptlínia & Sim & $5 \mathrm{~mm}$ \\
\hline Eslavóąuia & Sim & Sim & Ptatugrel & NEo & No \\
\hline Estrựinia & Sim & Sim & Raino Unidp & Sim & Sim \\
\hline Esprink & Sim & Sim & Roúlilon Taxo & Sin & $5 \mathrm{~m}$ \\
\hline Esticria & Sin & Sim & Ramê̄nia & Sim & Sim \\
\hline Finlfindix & NEo & Sin & Rícsia & Sim & Sin \\
\hline Frange & Sim & Sim & Servia e Mambarisp & NEo & N5p \\
\hline Gúin & NEo & Nop & Suécia & $\mathbf{N E o}$ & Sim \\
\hline Holmde & Sim & Sim & Sorípa & Sim & Sim \\
\hline Humgria & Sim & Sim & Tureyuix & NEo & K5 \\
\hline Idrmdn & NEs & $\mathbf{H}$ & Ukêtî & Sim & $5 \mathrm{~mm}$ \\
\hline Elindia & NEo & Nop & & & \\
\hline
\end{tabular}

Fonte: O autor a partir de EEA, 2005

(2002) observou que as análises não permitem afirmar que a cobrança apresenta eficiência econômica, ou seja, é capaz de internalizar integralmente as externalidades, porque, para tal, seria necessário o cálculo do VERA. Mas, analisando os valores cobrados em países membros da Organização para a Cooperação e Desenvolvimento Econômico (OCDE), concluiu como limitada a capacidade da aplicação deste instrumento, aplicado de forma isolada, induzir adequações de comportamentos, pelo fato dos valores cobrados serem baixos, não representando um estímulo relevante à redução do consumo ou tratamento dos efluentes.

Mesmo considerando a cobrança o instrumento de melhor adequação às particularidades da gestão de recursos hídricos de uma bacia, Santos (2002) concluiu - a exemplo do mencionado anteriormente por EEA (2005) - que a cobrança não vem sendo aplicada como IE, mas como instrumento arrecadador, onde os valores são fixados para cobrir custos dos sistemas de gestão, como ocorre na Inglaterra e País de Gales; gerar recursos para financiar parte dos investimentos contemplados nos planos de bacia, como se verifica na França; ou como ressarcimento às agências dos custos incorridos para tratamento dos efluentes nas estações sob sua responsabilidade, como no sistema holandês.

Esta seção buscou apresentar de forma sucinta a experiência internacional na cobrança pelo uso da água. A próxima traz a discussão para o âmbito brasileiro.

\section{A EXPERIÊNCIA BRASILEIRA NA COBRANÇA PELO USO DA ÁGUA}

No Brasil a Lei 9433/1997, no seu artigo $5^{\circ}$, relaciona a cobrança entre os instrumentos da Política Nacional de Recursos Hídricos. Os artigos $19^{\circ}$ ao $21^{\circ}$ são destinados a disciplinar a cobrança. O artigo $19^{\circ}$ relaciona os objetivos: (i) reconhecer a água como bem econômico e dar ao usuário 
uma indicação de seu real valor; (ii) incentivar a racionalização do uso da água; e (iii) obter recursos financeiros para o financiamento dos programas e intervenções contemplados nos planos de recursos hídricos. O artigo $20^{\circ}$ determina que serão cobrados (todos) os usos sujeitos à outorga citados no artigo $12^{\circ}$ : (i) derivação ou captação de parcela da água existente em um corpo de água para consumo final, inclusive abastecimento público, ou insumo de processo produtivo; (ii) extração de água de aquífero subterrâneo para consumo final ou insumo de processo produtivo; (iii) lançamento em corpo de água de esgotos e demais resíduos líquidos ou gasosos, tratados ou não, com o fim de sua diluição, transporte ou disposição final; (iv) aproveitamento dos potenciais hidrelétricos; (v) outros usos que alterem o regime, a quantidade ou a qualidade da água existente em um corpo de água. $\mathrm{O}$ artigo $22^{\circ}$ orienta a destinação dos valores arrecadados: (i) financiamento de estudos, programas, projetos e obras incluídos nos Planos de Recursos Hídricos; e (ii) no pagamento de despesas de implantação e custeio administrativo dos órgãos e entidades integrantes do Sistema Nacional de Gerenciamento de Recursos Hídricos. Esta legislação, no artigo $44^{\circ}$ definiu como competência das Agências de Água propor aos Comitês de Bacias Hidrográficas os valores a serem cobrados pelo uso dos recursos hídricos (BRASIL, 1997).

Segundo a Agência Nacional de Águas3 - ANA (2012b) - em bacias de âmbito federal a cobrança encontra-se implementada desde março/2003 nos rios de domínio da União das BH do Rio Paraíba do Sul e desde janeiro de 2006 dos Rios Piracicaba, Capivari e Jundiaí (PCJ). Na BH do Rio São Francisco a cobrança teve início em julho/2010 e do Rio Doce desde novembro/2011. Com respeito à cobrança pelo uso da água em bacias estaduais, em 2009 estava implementada no Rio de Janeiro, em todas as bacias do estado; em São Paulo, nos rios estaduais das Bacias PCJ e Paraíba do Sul, e nas Bacias do Rio Sorocaba e Médio Tietê; em Minas Gerais, a partir de 2010 na porção mineira das Bacias PCJ (Bacias PJ), na Bacia do Rio das Velhas e na Bacia do Rio Araguari, e em 2011 nos afluentes do Rio Doce.

Quadro 1 - Aspectos relativos às metodologias implementadas pelo CEIVAP e Comitê PCJ

\begin{tabular}{|l|l|}
\hline Aspecto & Implementação \\
\hline Captação & Utilização da vazão efetivamente captada \\
\hline $\begin{array}{l}\text { Dominialidade } \\
\text { (federal ou estadual) }\end{array}$ & $\begin{array}{l}\text { Diferenciação do consumo de cada dominialidade, para viabilizar o } \\
\text { rateio das receitas entre Governo Federal e Estados }\end{array}$ \\
\hline Diluição & $\begin{array}{l}\text { Consideração do volume anual de água necessário para diluir a } \\
\text { carga de DBO, ponderada a concentração permitida em função do } \\
\text { enquadramento }\end{array}$ \\
\hline Classe de captação & $\begin{array}{l}\text { Cobrança diferenciada em função da qualidade da água nos pontos de } \\
\text { captação }\end{array}$ \\
\hline Irrigação & Adoção de um coeficiente específico para o setor \\
\hline Setor rural & $\begin{array}{l}\text { Adoção de coeficientes específicos para o setor, com o objetivo de } \\
\text { reduzir a cobrança }\end{array}$ \\
\hline $\begin{array}{l}\text { Recursos para a } \\
\text { gestão }\end{array}$ & $\begin{array}{l}\text { Adoção de um coeficiente específico visando garantir o retorno dos } \\
\text { recursos arrecadados às bacias de origem }\end{array}$ \\
\hline Diferenciação por uso & $\begin{array}{l}\text { Adoção de valores diferenciados para cada tipo de uso, inclusive para } \\
\text { geração elétrica }\end{array}$ \\
\hline $\begin{array}{l}\text { Abatimentos por } \\
\text { investimentos }\end{array}$ & $\begin{array}{l}\text { Permite ao usuário abater parte do valor investido em açães de } \\
\text { reduções na DBO }\end{array}$ \\
\hline
\end{tabular}

Fonte: O autor, a partir de Carvalho et al. (2006)

3 A ANA foi criada pela Lei 9.984/2000 como uma autarquia sob regime especial, com autonomia administrativa e financeira, vinculada ao Ministério do Meio Ambiente. Entre suas atribuições está a implementação, em articulação com os Comitês de Bacia Hidrográfica, da cobrança pelo uso de recursos hídricos de domínio da União (BRASIL, 2000) 
Diversos estudos relativos à implementação da cobrança, pormenorizando as metodologias adotadas em diversos dos casos citados, podem ser encontrados em ANA (2012a). Em uma das publicações relacionadas, Carvalho et al. (2006) analisa as metodologias adotadas para a cobrança implementadas pelo comitê da bacia do rio Paraíba do Sul (CEIVAP) e comitê PCJ. O comitê PCJ aproveitou a experiência anterior do CEIVAP, que também revisou a sua metodologia em 2006. O Quadro 1 relaciona aspectos contemplados nas duas metodologias.

Embora a legislação brasileira disponha de toda a normatização necessária para a plena implantação da cobrança como efetivo IE, sua implementação no país é lenta e tímida. Esta constatação foi ilustrada por Cánepa et al. (2010) em quatro pontos: (i) na diluição apenas um poluente é contemplado, a Demanda Bioquímica de Oxigênio (DBO); (ii) os valores cobrados são baixos, não atingindo caráter incitativo; (iii) os valores cobrados não estão inseridos dentro de um planejamento custo-efetivo de aumentos progressivos; (iv) a cobrança como IE não está bem absorvida pelos órgãos ambientais e pelos juristas da área do Direito Ambiental4.

Cánepa et al. (2010) ponderam que implantação da cobrança como efetivo IE apresenta grande atraso em relação ao que já foi obtido por países avançados. Observamos que a afirmação é verdadeira quanto à extensão da aplicação da cobrança comparativamente a magnitude dos recursos hídricos brasileiros. Mas quanto à qualidade da aplicação do instrumento, as deficiências verificadas na implantação brasileira são as mesmas verificadas na seção anterior, relativa à experiência internacional.

No estado do Rio Grande do Sul (RS) a cobrança ainda não teve inicio. A situação representa uma ameaça, considerando-se a situação dos recursos hídricos do estado, mas também a oportunidade de evitar-se, quando da implantação, falhas mostradas pela experiência histórica. A cobrança no RS é o tema da próxima seção.

\section{A COBRANÇA PELO USO DA ÁGUA NO RIO GRANDE DO SUL}

O território do RS compreende três regiões hidrográficas - Uruguai, Guaíba e Litoral, formadas por $25 \mathrm{BH}$. Estudos de alternativas de gestão para a sustentabilidade destas águas são amplamente justificáveis em face da situação crítica que este recurso natural se apresenta em muitas bacias, tanto em termos qualitativos como quantitativos. A identificação de criticidade das bacias, baseada no artigo 20 do Decreto 37.033/1996, é apresentada na Tabela 2.

A Tabela 2 mostra doze $\mathrm{BH}$ com restrições, em nove a disponibilidade de águas superficiais é considerada crítica e em seis a qualidade da água é considerada crítica. Ponderadas as águas subterrâneas, as piores situações foram encontradas nas BH do Gravataí, Sinos, Caí, Lago Guaíba, Mampituba, Santa Maria e Negro. Segundo Ecoplan (2007, p.106), tomando-se a BH do Rio dos Sinos como exemplo temos as seguintes situações de conflito:

insuficiência hídrica nos meses de verão; lançamentos de esgotos domésticos pouco ou não tratados, comprometendo a qualidade das águas, principalmente em situações de baixas vazões e no trecho médio-baixo; lançamentos de efluentes industriais acima da capacidade de assimilação do Rio em períodos de baixas vazões, no trecho médio-baixo; conflito de quantidade entre abastecimento humano e irrigação; conflito de qualidade entre os lançamentos de esgotos e efluentes com outros usos, principalmente o abastecimento humano, lazer e preservação ambiental; disposição indevida de resíduos sólidos na Região Metropolitana de Porto Alegre, gerando contaminação de recursos hídricos; mau uso do solo e desmatamento nas encostas, gerando processos erosivos e modificações no balanço hídrico.

Foi justamente visando a melhoria na qualidade e quantidade das águas que o artigo 171 da Constituição estadual do RS, promulgada em 1989, instituiu o Sistema estadual de recursos hídricos (SERH), integrado ao sistema nacional, adotando as BH como unidades básicas de planejamento e gestão, onde o inciso terceiro especificou que "os recursos arrecadados pela utilização da água deverão ser destinados a obras e à gestão dos recursos hídricos na própria bacia, garantindo sua conservação

4 No tocante à diluição prevalece os limites legais previstos por C\&C, que são estáticos. A cobrança como IE é dinâmica no sentido de estabelecer níveis variados dependendo dos objetivos de enquadramento, que por sua vez variam por trechos de cada rio ou arroio. 
Tabela 2 - Análises de Criticidade da Bacias Hidrográficas do Rio Grande do Sul

\begin{tabular}{|c|c|c|c|c|}
\hline $\begin{array}{l}\text { BH / Região } \\
\text { Hidrográfica }\end{array}$ & $\begin{array}{l}\text { Disponibilidade } \\
\text { e uso de águas } \\
\text { superficiais }\end{array}$ & $\begin{array}{l}\text { Qualidade } \\
\text { das águas } \\
\text { superficiais }\end{array}$ & $\begin{array}{c}\text { Disponibilidade } \\
\text { e uso de águas } \\
\text { subterrâneas }\end{array}$ & $\begin{array}{c}\text { Qualidade } \\
\text { das águas } \\
\text { subterrâneas } \\
\end{array}$ \\
\hline G010 - Gravataí & Crítica & Crítica & Crítica & Com restrição \\
\hline G020 - Sinos & Crítica & Crítica & Crítica & Com restrição \\
\hline G030 - Caí & Alerta & Crítica & Crítica & Sem restrição \\
\hline G040 - Taquari - Antas & Confortável & Crítica & Alerta & Sem restrição \\
\hline G050 - Alto Jacuí & Confortável & Alerta & Confortável & Sem restrição \\
\hline $\begin{array}{l}\text { G060 - Vacacaí - Vacacaí- } \\
\text { Mirim }\end{array}$ & Crítica & Alerta & Confortável & Com restrição \\
\hline G070 - Baixo Jacuí & Confortável & Confortável & Confortável & Com restrição \\
\hline G080 - Lago Guaíba & Confortável & Crítica & Crítica & Com restrição \\
\hline G090 - Pardo & Confortável & Alerta & Alerta & Com restrição \\
\hline L010 - Tramandaí & Alerta & Confortável & Confortável & Sem restrição \\
\hline L020 - Litoral Médio & Crítica & Confortável & Confortável & Sem restrição \\
\hline L030 - Camaquã & Alerta & Confortável & Confortável & Sem restrição \\
\hline $\begin{array}{l}\text { L040 - Mirim - São } \\
\text { Gonçalo }\end{array}$ & Crítica & Confortável & Confortável & Com restrição \\
\hline L050 - Mampituba & Crítica & Alerta & Alerta & Sem restrição \\
\hline $\begin{array}{l}\text { U010 - Apuaê - } \\
\text { Inhaldava }\end{array}$ & Confortável & Alerta & Confortável & Sem restrição \\
\hline U020 - Passo Fundo & Confortável & Alerta & Confortável & Sem restrição \\
\hline $\begin{array}{l}\text { U030 - Turvo - S.Rosa - } \\
\text { S.Cristo }\end{array}$ & Confortável & Crítica & Confortável & Com restrição \\
\hline U040 - Piratinim & Confortável & Confortável & Confortável & Sem restrição \\
\hline U050 - Ibicuí & Alerta & Confortável & Confortável & Com restrição \\
\hline U060 - Quaraí & Alerta & Confortável & Confortável & Sem restrição \\
\hline U070 - Santa Maria & Crítica & Confortável & Confortável & $\begin{array}{l}\text { Com } \\
\text { Restrição } \\
\end{array}$ \\
\hline U080 - Negro & Crítica & Alerta & Alerta & Com restrição \\
\hline U090 - Ijuí & Confortável & Alerta & Confortável & Sem restrição \\
\hline U100 - Várzea & Confortável & Alerta & Confortável & Com restrição \\
\hline U110 - Butuí - Icamaquã & Crítica & Confortável & Confortável & Sem restrição \\
\hline
\end{tabular}

Fonte: Ecoplan, 2007

e a dos recursos ambientais, com prioridade para as ações preventivas" (RS, 1989). A regulamentação deste artigo, ocorrida em 1994 quando da promulgação da lei 10.350, permitiu o delineamento da estrutura estadual de gestão dos recursos hídricos, apresentado na figura 1 (RS, 1994).

Entre os princípios estabelecidos no artigo terceiro definiu que "as diversas utilizações da água serão cobradas, com a finalidade de gerar recursos para financiar a realização das intervenções necessárias à utilização e à proteção dos recursos hídricos, e para incentivar a correta utilização da água". No artigo quarto o texto legal assume o compromisso de apoiar tecnicamente os comitês de bacias criação de Agências de Região Hidrográfica. No artigo sexto consta a proposição, execução e 


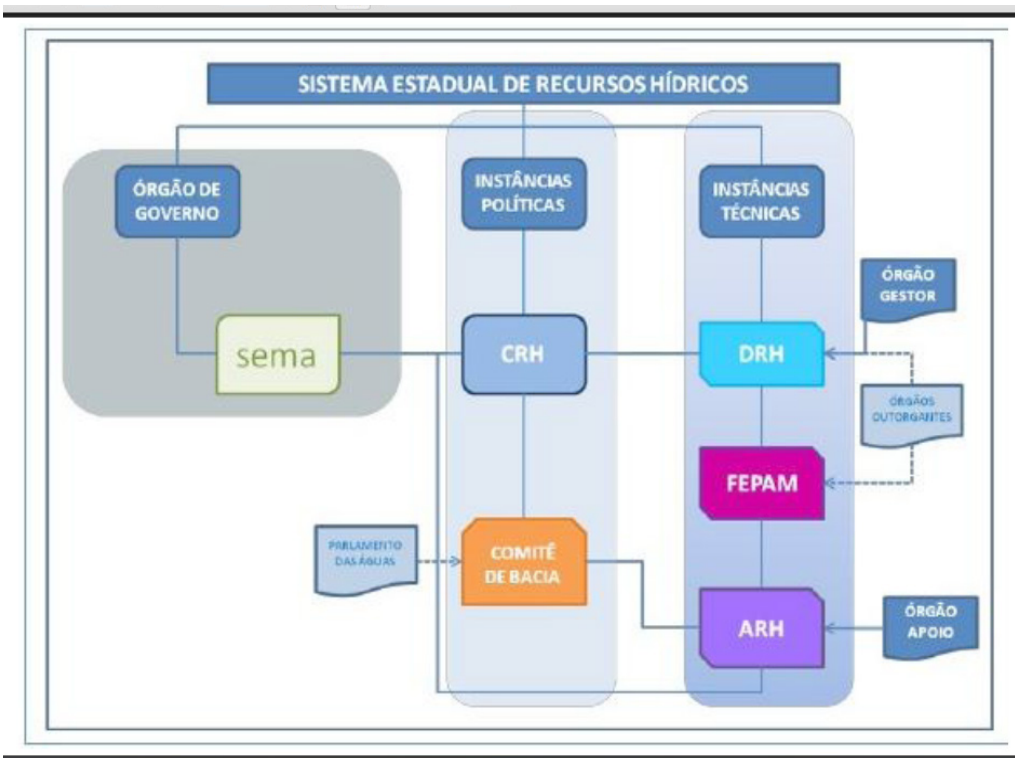

Figura 1 - Sistema de Gestão de Recursos Hídricos no Rio Grande do Sul

Fonte: Sema, 2012

Siglas: Sema-Secretaria de Meio Ambiente; CRH - Conselho de Recursos Hídricos; DRH - Departamento de Recursos Hídricos; FEPAM - Fundação Estadual de Proteção Ambiental.

atualização dos Planos das BH e do PERH. Entre as atribuições dos comitês (19 ${ }^{\circ}$ artigo) constou a aprovação dos valores a serem cobrados pelo uso da água da $\mathrm{BH}$ e a realização do rateio dos custos de obras de interesse comum a serem executadas. Compete às ARH arrecadar e aplicar os valores correspondentes à cobrança pelo uso da água de acordo com o plano de cada bacia (artigo 20) e ao PERH as diretrizes para a cobrança (artigo 23). Ainda, a seção 2 (artigos 32 e 33) e a seção 3 (artigo 34) disciplinam a cobrança e o rateio de custos das obras. Estabelece que os valores arrecadados na cobrança serão aplicados exclusivamente na bacia de origem, considerando na captação os seguintes elementos: (i) o uso a que se destina, (ii) o volume captado e seu regime de variação, (iii) o consumo efetivo, e (iv) a classe preponderante de enquadramento. Na diluição, sem prejuízo ao cumprimento das normas e padrões legais, estabelece que deverão ser considerados: (i) a natureza da atividade geradora do efluente, (ii) a carga lançada e o regime de variação, ponderados parâmetros físicos, químicos, biológicos e toxicidade dos efluentes, (iii) a classe de uso preponderante de enquadramento, (iv) o regime de variação quantitativa e qualitativa do corpo de água receptor. Por fim, o artigo 40 ainda estabelece que a implantação da cobrança ocorra de forma gradativa, com o desenvolvimento de programa de comunicação social, apoiado pela implantação de um sistema de informações hidrometeorológicas e cadastro dos usuários, além da implantação de um sistema integrado de outorga, compatibilizado com os sistemas de licenciamento ambiental, abrangendo os usos existentes, que deverão adaptar-se ao novo dispositivo legal (RS, 1994).

Passados quase vinte anos da promulgação, à luz das experiências internacionais e brasileiras relatadas nas seções anteriores, observa-se que este dispositivo legal permanece atualizado e alinhado com o propósito maior do uso da cobrança como IE, a indução dos agentes econômicos à utilização sustentável dos recursos hídricos. A leitura cuidadosa mostra tratar-se de um marco legal bem acabado em termos coerência e aplicabilidade. Não obstante a isso, sua implementação vem ocorrendo em ritmo extremamente lento, principalmente pela indefinição do plano estadual e a falta de agências de águas.

O plano estadual está em elaboração há anos. A primeira etapa, de diagnóstico - disponibilidades, demandas e balanço hídrico, foi finalizada em 2007. A segunda, da compatibilização de cenários, foi concluída em 2011. No final daquele ano ocorreram as reuniões para acordos políticos visando a formatação dos programas de ações a serem contemplados no plano. Estão pendentes a terceira etapa - definição de metas e elaboração do relatório final e a quarta etapa - elaboração do anteprojeto de lei. Compõem a terceira etapa: (i) a elaboração do plano propriamente dito, com a proposição de 
alternativas de intervenção, definição de programas e de alternativas de financiamento, e as diretrizes para a cobrança; (ii) diretrizes de articulação para alcançar-se o enquadramento; (iii) diretrizes para a consolidação da outorga; e a (iv) organização para a implementação do plano (ECOPLAN, 2011). Diversos comitês têm procurado desenvolver seus planos, que invariavelmente ficam inacabados por dependerem de definições a serem contempladas no plano estadual, e pela precariedade da atuação da ARH.

Numa tentativa de dinamizar a gestão de RH do Estado, em março de 2010 o Governo do Estado, através da Secretaria do Meio Ambiente (Sema), firmou convênio de cooperação técnica e financeira com a Fundação Estadual de Planejamento Metropolitano e Regional (Metroplan) para atuação como agência da Região Hidrográfica do Guaíba (SEMA, 2010). Como a Metroplan não dispôs de estrutura adequada para o desempenho dessa nova atribuição5, os resultados foram modestos6, de modo que a segunda renovação do convênio, cuja vigência acaba em setembro de 2012, está sob avaliação7.

A análise da prática internacional somada ao acompanhamento dos resultados obtidos nos dez anos da experiência nacional na aplicação da cobrança, quando confrontados com o texto legal da Lei 10.340/1994, mostra que o cumprimento adequado dos preceitos legais pode permitir a implementação deste IE em bases adequadas, pois a legislação:

prevê a utilização dos recursos captados "exclusivamente" nas bacias de origem - permite aos usuários o acompanhamento da arrecadação e a participação da discussão da destinação dos recursos, podendo observar diretamente os resultados - melhorias de qualidade e quantidade - e cobrar do Comitê e ARH correções, quando necessário;

permite diferenciações na cobrança em função do uso/usuário - tanto na captação como na diluição, a exemplo do que ocorre na experiência brasileira com o setor rural, irrigação e setor elétrico, e na UE para a manutenção da competitividade industrial;

permite ponderações financeiras sobre o volume captado ou diluído e seu regime de variação cobrar apenas sobre o que é consumido/diluído efetivamente é uma forma de estimular a redução do consumo/emissão e premiar a eficiência de uso da água. Também, permite a diferenciação da cobrança para a captação e diluição em períodos de estiagem em relação aos períodos de excedentes hídricos; permite diferenciar a cobrança em função da classe de enquadramento - como os custos são diferenciados em função do nível de qualidade estabelecidos para cada local, nada mais justo que a cobrança também ocorra de forma diferenciada. Esta prática vem sendo usada no Brasil;

prevê ponderação sobre parâmetros físicos, químicos, biológicos e toxicidade dos efluentes - a experiência brasileira tem contemplado apenas a DBO, porém a legislação esta aberta à inclusão de outras substâncias nocivas, a exemplo da experiência internacional;

prevê a implementação de forma gradativa, apoiada por sistema de comunicação social, sistema de informações hidrometeorológicas, cadastro de usuários e sistema "integrado" de outorga - são aspectos essenciais para uma implementação bem sucedida: como toda implementação bem planejada, é desejável que a implantação ocorra de forma gradativa a partir de um piloto, de modo a corrigir falhas e permitir aperfeiçoamentos do processo, evitando a multiplicação de eventuais desgastes nas imagens institucionais e na credibilidade do IE. A cobrança é um instrumento complexo de gestão, que demanda uma estrutura organizacional robusta para a implementação8. Ainda, como lembra Cánepa et al. (2010), a cobrança como IE sequer está bem absorvida pelos órgãos ambientais e pelos juristas da área do Direito Ambiental. É natural a resistência ao pagamento por algo até então gratuito, de modo que a implantação exige forte disposição política e sua manutenção, um organizado sistema de cadastramento, outorga e fiscalização. A experiência internacional ensina que a cobrança não pode ser aplicada isoladamente, precisa de um conjunto de ações para levar à indução via mudanças de atitudes frente aos $\mathrm{RH}$.

Além das orientações contidas no marco legal, a literatura consultada permitiu a identificação de outros aspectos a serem considerados: (i) a incorporação de abatimentos na cobrança por investimentos realizados pelos usuários que resultem em redução na captação ou na carga poluidora; (ii) a inclusão da cobrança sobre a captação ou diluição em águas subterrâneas; (iii) a diferenciação de preços

\footnotetext{
5 A Metroplan conta com 98 profissionais atuando em projetos e obras, principalmente na área de transportes, em atuação que em muitos casos adquire amplitude estadual (METROPLAN, 2012a)

6 As realizações estão listadas no portal da Metroplan (METROPLAN, 2012b).

7 Informação relatada oralmente durante a reunião oridanária do Comitê da BH Sinos, ocorrida em 13 de setembro de 2012.

8 Recomendamos ao leitor o acesso à apresentação ANA (2011).
} 
entre descargas diretas e indiretas; (iv) a racionalização da fiscalização sobre a diluição, de modo a controlar as descargas tanto sob o ponto de vista da cobrança como do cumprimento da legislação de emissões máximas; e (v) viabilizar a integração de planejamento entre os Conselhos Regionais de Desenvolvimento (COREDES) e os Comitês de BH.

As principais deficiências de implementação da cobrança, identificadas na literatura como comum à experiência internacional e brasileira, foram: a manutenção de valores muito baixos de cobrança, que não conferem ao instrumento o caráter incitativo; e o uso da cobrança apenas como instrumento arrecadador, dissociado de um planejamento custo-efetivo de aumentos progressivos.

\section{CONCLUSÕES}

Grande parte dos mananciais hídricos do estado do Rio Grande do Sul, superficiais e subterrâneos, encontra-se em estado crítico, tanto sob o ponto de vista da captação, que sofre pela significativa variação natural nos níveis de vazão ao longo do ano, resultando em conflitos pelo uso, como do ponto de vista da diluição, onde muitos arroios se transformaram em verdadeiros esgotos a céu aberto.

Há dezoito anos o Estado conta com uma legislação alinhada às melhores práticas mundiais a Lei 10350/1994 - que permanece carente de regulamentação: os serviços de cadastro e outorga são deficientes, há anos o plano estadual de recursos hídricos encontra-se em elaboração e não existem Agências de Águas funcionando em caráter permanente. Ainda, prevê-se que as "sociedades das Bacias" não serão simpáticas a cobrança pelo uso da água e reações enfáticas devem ser esperadas.

Este cenário representa uma grande ameaça, que inevitavelmente resultará em ações políticas concretas de reversão. Mas, como as principais ações ainda estão por vir, existe a oportunidade das suas implantações ocorrerem de forma qualificada. Com o intuito de colaborar com a discussão, este artigo analisou a experiência internacional e nacional no uso da cobrança pelo uso da água visando apresentar contribuições no sentido da introdução com qualidade deste instrumento econômico no Estado.

A revisão da literatura mostra que a prática brasileira, em curso desde 2003, pouco perde para as melhores práticas internacionais, mas existem importantes deficiências de aplicação que são comuns aos casos analisados. No primeiro caso temos que na diluição o Brasil tem considerado apenas um parâmetro, a DBO, ao passo que na experiência internacional chegam a ser consideradas até trinta substâncias diferentes, como no caso da Romênia. É falha geral a cobrança ser custo-efetiva na plenitude, pois ora é usada como simples instrumento arrecadador e ora é aplicada com preços baixos e estáticos, não indutores ao comportamento desejado. E, principalmente, não é planejada prevendo-se aumentos graduais de valores de cobrança combinados com novos patamares de metas, visando o atingimento da qualidade e quantidade desejados em um prazo pré-estabelecido.

\section{REFERÊNCIAS}

AGÊNCIA NACIONAL DAS ÁGUAS (ANA). Cobrança pelo uso de recursos hídricos: textos e estudos. Disponível em: <http://www.ana.gov.br/CobrancaUso/EstudosCobranca.asp>. Acesso em: 12 set. 2012.a

Conjuntura dos Recursos Hídricos no Brasil: informe 2012. Disponível em: < $\underline{\text { http://arquivos.ana.gov. }}$ br/imprensa/arquivos/Conjuntura2012.pdf > . Acesso em: 12 set. 2012.b

Oficina de Avaliação da Gestão de Recursos Hídricos no Rio Grande do Sul: Discussão em Grupo. Novembro de 2011. ANA/Sema. Disponível em: <http://www.google.com.br/url?sa=t\&rc

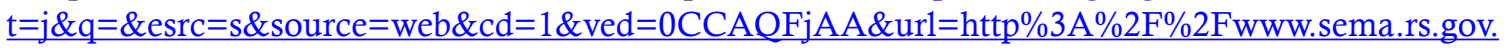
br\%2Fupload\%2FDinamica e agenda ANA RS.ppt\&ei=TDdWUPGrEIPq9ATm3oEw\&usg=AFQjCNGU X59oHdqt9BowmuSUF4cCDPk76w\&sig2=MytHzY2pdwOrwccSIx Ktw>. Acesso em: 16 set. 2012.

ALMEIDA, L.T.. O debate internacional sobre Instrumentos de Política Ambiental e Questões para o Brasil. Artigo. [199-?]. Disponível em: <www.ecoeco.org.br/conteudo/publicacoes/encontros/ii en/mesa1/3.pdf > . 
Acesso em: 16 maio 2009.

BICUDO, C. E. M. et al.. Síntese. In: Águas do Brasil: Análises Estratégicas. Org: Bicudo, C. E. M.; Tundisi, J. G.; Scheuenstuhl, M. C. B.. São Paulo, Instituto de Botânica, 2010. Disponível em: <http://www.abc.org. br/IMG/pdf/doc-805.pdf>. Acesso em: 08 set. 2011.

BRASIL. Lei 9.433, de 8 de janeiro de 1997. Institui a Política Nacional de Recursos Hídricos, cria o Sistema Nacional de Gerenciamento de Recursos Hídricos, regulamenta o inciso XIX do art. 21 da Constituição Federal, e altera o art. $1^{\circ}$ da Lei $n^{\circ} 8.001$, de 13 de março de 1990, que modificou a Lei ${ }^{\circ} 7.990$, de 28 de dezembro de 1989. Disponível em: <http://www.planalto.gov.br/ccivil 03/LEIS/19433.htm>. Acesso em: 12 set. 2012 .

Lei 9.984, de 17 de julho de 2000. Dispõe sobre a criação da Agência Nacional de Águas - ANA, entidade federal de implementação da Política Nacional de Recursos Hídricos e de coordenação do Sistema Nacional de Gerenciamento de Recursos Hídricos, e dá outras providências. Disponível em: $<\underline{\text { http://www. }}$ sigrh.sp.gov.br/sigrh/basecon/lrh2000/LF/Leis/lf9984ana.htm>. Acesso em: 12 set. 2012.

CÁNEPA, E. M.. Água e Economia. In: Águas do Brasil: Análises Estratégicas. Org: Bicudo, C. E. M.; Tundisi, J. G.; Scheuenstuhl, M. C. B.. São Paulo, Instituto de Botânica, 2010. Disponível em: < http://www.abc. org.br/IMG/pdf/doc-805.pdf > . Acesso em: 08 set. 2011.

CARVALHO, G. B. B. A Cobrança pelo uso da Água nas Bacias dos Rios Paraíba do Sul e PCJ em 2006: avaliação e evolução. Disponível em: < http://www.ana.gov.br/GestaoRecHidricos/CobrancaUso/_ARQS-Estudos/Geral/02.pdf >. Acesso em: 12 set. 2012.

ECOPLAN ENGENHARIA. Apresentação dos Programas de Ações. Fase C: Eventos Públicos para Construção de Acordos Políticos do Programa de Ações. Ecoplan/Governo do Rio Grande do Sul. Outubro de 2011. Disponível em: <http://www.perh-rs.com.br/?sec=82>. Acesso em: 14 set. 2012.

Relatório Síntese da Fase A - RSA. Diagnóstico e Prognóstico Hídrico das Bacias Hidrográficas do Rio Grande do Sul. Ecoplan/Governo do Rio Grande do Sul Junho de 2007. Disponível em: <http://www. perh-rs.com. $b r /$ sec $=82 \&$ vertodas $=$ ok $>$. Acesso em: 14 set. 2012 .

ECOTEC. Study on the economic and environmental implications of the use of environmental taxes and charges in the European Union and Member States. Disponível em: <http://ec.europa.eu/environment/enveco/taxation/index. $\underline{\mathrm{htm}}$ >. Acesso em: 11 set. 2012.

FUNDAÇÃO ESTADUAL DE PLANEJAMENTO METROPOLITANO E REGIONAL (METROPLAN). Áreas de atuação. Disponível em: < http://www.metroplan.rs.gov.br/institucional/area atua.htm>. Acesso em: 14 set. 2012.a

Bacias Hidrográficas: Apoio ao Planejamento e à Gestão de Recursos Hídricos. Disponível em: $<$ http://www.metroplan.rs.gov.br/meio ambiente/bacias.htm\#top >. Acesso em: 14 set. 2012.b

MOTTA, R. S.. Economia Ambiental. Rio de janeiro : Editora FGV, 2006.

RIO GRANDE DO SUL. Constituição do Estado do Rio Grande do Sul. Texto constitucional de 3 de outubro de 1989. Disponível em: <http://www.al.rs.gov.br/prop/legislacao/constituicao/constituicao.htm>. Acesso em: 12 set. 2012.

Lei 10.350, de 30 de dezembro de 1994. Disponível em: <http://www.al.rs.gov.br/Legis/M010/ M0100099.ASP?Hid Tipo $=$ TEXTO\&Hid TodasNormas $=12501 \&$ hTexto $=\&$ Hid IDNorma $=12501>$. Acesso em: 15 set. 2012. 
SANTOS, M. O. R. M.. O Impacto da Cobrança pelo Uso da Água no Comportamento do Usuário. Tese Universidade Federal do Rio de Janeiro, COPPE, 2002.

SECRETARIA DO MEIO AMBIENTE (SEMA). Governadora cria agência pioneira na gestão de recursos hídricos do RS. 2010. Disponível em: <http://www.sema.rs.gov.br/> . Acesso em: 14 de set. 2012.

. Sistema Estadual de Recursos Hídricos. Disponível em: < http://www.sema.rs.gov.br/upload/SERH esquema.pdf>. Acesso em: 16 de set. 2012.

SOUZA, O. T. et al.. Instrumentos de política ambiental aplicáveis às águas: conflitos na cobrança pelo uso da água no Lago Guaíba. Disponível em: <http://revistas.fee.tche.br/index.php/ensaios/article/ view/2580/2924>. Acesso em: 08 set. 2011.

UNIÃO EUROPEIA (UE). Diretiva 60/2000-CE. Estabelece um quadro de ação comunitária no domínio da política da água. Disponível em: < http://eur-lex.europa.eu/LexUriServ/LexUriServ.do?uri=OJ:L:2000:327:0 001:0072:PT:PDF>. Acesso em: 11 set. 2012.

UNITED NATIONS EDUCATIONAL, SCIENTIFIC AND CULTURAL ORGANIZATION (UNESCO). Managing Water under Uncertainty and Risk. The United Nations World Water Development Report 4.

2012. Disponível em: <http://www.unesco.org/new/en/natural-sciences/environment/water/wwap/wwdr/ wwdr4-2012/>. Acesso em: 16 set. 2012.

UNIVERSIDADE DO VALE DO RIO DOS SINOS (UNISINOS). Plano Sinos: Plano de Gerenciamento da Bacia Hidrográfica do Rio dos Sinos. Meta 5. Atividade 5.3 - Síntese do Plano de Bacia. Consórcio Pró-Sinos e Comitesinos. [2011]. Disponível em: $<$ http://www.consorcioprosinos.com.br/downloads/PBHSINOS-R10-Volume\%20\%C3\%9Anico.pdf>. Acesso em: 08 set. 2011. 